\title{
Conociendo nuestra población a través de las emociones
}




\section{Resumen}

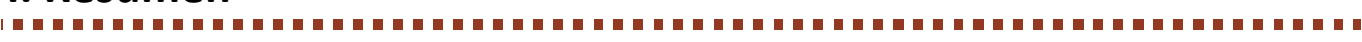

La experiencia que presentamos en este artículo abre las puertas a nuevas ideas, perspectivas, conocimientos, impresiones e imágenes aportadas por niños y niñas. Los y las más pequeñas nos ofrecen una visión diferente de la población a través de sus gustos y emociones. En esta iniciativa han participado un total de 18 alumnos y alumnas de primero de educación primaria de un centro educativo situado en la provincia de Castellón. A través de entrevistas, observación participante y un cuestionario se han descubierto los lugares que más gustan y los que menos gustan de la localidad. Para ello, a través de un mapa, el alumnado ha identificado y ubicado elementos de la realidad $y$ ha reconocido las emociones $y$ sensaciones que les evocaba cada lugar. Se han utilizado emoticonos y se ha creado de forma cooperativa un mapa emocional. Posteriormente, se trabajó sobre el monumento más rechazado por las emociones del alumnado, el lavadero de la localidad, con la intención de que lo conozcan y que cuando pasen por su lado lo miren de una manera diferente, y así se consiga que sea uno de los puntos más queridos por los protagonistas de esta experiencia. Además, se ha reflejado con entrevistas qué cambiarían y qué no de cada lugar trabajado, con lo que se han sabido las ventajas y los defectos de la localidad. Los resultados demuestran un mayor interés del alumnado y de los adultos por la población y por las emociones, mejora en las relaciones sociales y en el clima del aula gracias al trabajo en equipo, la responsabilidad y una posible continuidad del proyecto establecido.

Palabras clave: mapa emocional, educación emocional, aprendizaje cooperativo.

\section{Introducción}

El mapa emocional es un trabajo que se ha puesto en práctica en un colegio ubicado en la provincia de Castellón. Es una experiencia innovadora ya que permite a los niños y a las niñas aproximarse a su pueblo de una manera que nunca antes lo habían hecho, a través de sus propias emociones. Se ha llevado a cabo una serie de actividades para que los protagonistas de esta experiencia puedan proporcionar sus puntos de vista sobre diferentes lugares de su localidad con la finalidad de mejorar la ciudad desde la escuela (Sintes, 2005). Asimismo, uno de los ingredientes principales para la consecución del proyecto es el aprendizaje cooperativo mediante equipos de trabajo, donde todos los integrantes de la clase trabajan juntos con 
la intención de potenciar el propio aprendizaje y el de sus compañeros y compañeras, y así obtener unas metas comunes gracias a la participación de cada uno (Johnson, Johnson y Holubec, 1999).

Así como afirman otros autores (Tonucci, 2001; Jiménez, 2003; Tonucci, 2006), la ciudad debe adaptarse y mejorar con las ideas y propuestas de los niños y las niñas, y darles la oportunidad de crear un entorno mejor en el que «puedan salir de casa solos para vivir con sus amigos las experiencias fundamentales de la exploración, la aventura y el juego» (Tonucci, 2001: 10).

Los contenidos y las competencias clave que se han trabajado, según el Decreto 108/2014, de 4 de julio, por el que se establece el currículum y se desarrolla la ordenación general de la educación primaria en la Comunitat Valenciana, de las área de Ciencias Sociales y Matemáticas, son los que aparecen en la tabla 1:

Tabla 1. Áreas, contenidos y competencias clave según el Decreto 108/2014

\begin{tabular}{|c|c|c|}
\hline Áreas & Contenidos & $\mathrm{CC}$ \\
\hline Ciencias Sociales & $\begin{array}{l}\text { - Iniciación al método científico y su aplicación a las Ciencias } \\
\text { Sociales: formulación de preguntas, registro y organización } \\
\text { de información, imágenes y tablas, y elaboración de planos } \\
\text { - Representación del espacio geográfico: elementos del plano. } \\
\text { Elaboración de croquis para situar espacios cotidianos y } \\
\text { rutas. } \\
\text { - Participación cooperativa: escucha de aportaciones y } \\
\text { aportación de ideas propias constructivas. Ser responsable } \\
\text { del trabajo personal para conseguir una meta colectiva }\end{array}$ & $\begin{array}{l}\text { CCLI } \\
\text { CMCT } \\
\text { CAA } \\
\text { CSC } \\
\text { SIEE }\end{array}$ \\
\hline Matemáticas & $\begin{array}{l}\text { - Uso adecuado y mantenimiento de los instrumentos y } \\
\text { materiales utilizados } \\
\text { - Esforzarse. Constancia y hábitos de trabajo } \\
\text { - Representación de pictogramas. }\end{array}$ & CEC \\
\hline
\end{tabular}

\section{Objetivos}

El objetivo general de este artículo es dar a conocer esta experiencia educativa basada en las emociones. Por otro lado, los objetivos específicos son los siguientes: conseguir una nueva visión de la población, crear un mapa personalizado a través de las emociones y los lugares seleccionados por el alumnado, identificar y ubicar elementos de la realidad en un mapa de la localidad, respetar las normas de interacción oral, participar activamente y ser responsable del trabajo en el aula, crear un gráfico con las 
preferencias del alumnado y, por último, mejorar el clima del aula y las relaciones entre iguales.

Por tanto, las preguntas de investigación que nos planteamos son las siguientes: ¿Qué aspectos positivos y negativos resaltarán de la localidad? ¿Qué lugares serán los más deseados por el estudiantado? ¿Qué emociones reflejarán en cada lugar? ¿Existen diferencias entre antes y después de la experiencia en las relaciones sociales entre iguales?

\section{Método y desarrollo de la experiencia}

\section{Diseño de la investigación}

La investigación presenta un diseño cuasiexperimental con pretest y postest implementada en un grupo de estudiantes. Este proporciona argumentos más sólidos y un control razonable sobre la mayor parte de las fuentes de invalidez (Bisquerra, 2009). Asimismo, se precisa de una recogida sistemática de información mediante una observación participativa y un cuestionario sociométrico. Se ha implementado la intervención $y$, posteriormente, se ha recogido información para poder analizarla con los datos obtenidos en un primer momento. Además, se han anotado todos los datos obtenidos durante la experiencia mediante el diario de campo.

\section{Muestra}

En este estudio ha participado un total de 18 estudiantes de primero de educación primaria pertenecientes a un colegio de la provincia de Castellón, cuyas edades están comprendidas entre los seis y los siete años.

\section{Instrumentos y técnicas}

Los instrumentos empleados para la recogida de información son los siguientes:

- Observación participativa (diario de campo). Se pretende registrar todas las observaciones significativas y los datos durante el desarrollo de las actividades.

- Rúbrica de evaluación. Con este instrumento se pretende reflejar la consecución de los siguientes criterios: participación, buen comportamiento, actitud positiva y responsabilidad en los materiales.

- Batería de preguntas para la realización de las entrevistas. Algunas son las siguientes: ¿qué os gusta del parque? ¿Qué cambiarías del colegio? ¿Qué cambiarías del castillo? (alumnado) ¿Qué cosas te han Ilamado más 
la atención de esta experiencia? ¿Te ha gustado conocer los aspectos positivos y negativos de los lugares por parte del estudiantado? (maestra).

- Cuestionario sociométrico. Este instrumento nos permite conocer cuáles son las relaciones entre el estudiantado, es decir, si son positivas o negativas. Algunas preguntas son las siguientes: 1 . Nombra a tres compañeros de clase con los que estés más a gusto y sean tus amigos. ¿Por qué?, 2. Nombre a tres compañeros de clase con los que no te gustaría hacer los deberes. ¿Por qué?

- Mapa emocional. Técnica que nos permite conocer emocionalmente las perspectivas del alumnado sobre su propia población, en la que se proporcionan datos cuantitativos y cualitativos.

\section{Desarrollo de la experiencia}

Principalmente, y para conocer los lugares que destacan los niños y las niñas sobre su población, se repartieron unas hojas para que dibujaran el lugar que más les gusta de su localidad. Asimismo, se hizo con la finalidad de poder situar los lugares del pueblo en un mapa, según la importancia del alumnado, y poder trabajar a partir de sus conocimientos, gustos y experiencias. A continuación, se llevó a cabo la realización de una gráfica con los sitios destacados, con el fin de poder visualizar las preferencias y los intereses de cada uno.

Posteriormente, se formaron equipos de cuatro y cinco personas para trabajar cooperativamente en la siguiente actividad. A cada grupo se le proporcionó un póster titulado «El mapa emocional de nuestra población" y diez fotografías con los lugares que destacaron en los dibujos. Una vez repartido el material, colocaron las fotografías en el mapa según la ubicación correspondiente y con la ayuda de un mapa modelo situado en la pizarra. Asimismo, y para darle sentido al título del poster, se repartieron las emociones de alegría, tristeza, enfado, diversión y felicidad, las cuales debían colocar al lado de cada monumento del pueblo, según se sintieran. Una norma establecida es que solo podían utilizar una emoción por lugar. De esta manera, cada niño y niña indicó sus sentimientos y emociones, y crearon así sus mapas emocionales personalizados.

A raíz de esto, se repartió una ficha para profundizar sobre cada punto, que constaba de tres lugares elegidos. Al lado de cada uno debían poner con qué personas van a ese sitio, pegar una emoción y, a la derecha de esta, razonar el porqué de su selección.

Finalmente, se hizo una entrevista al alumnado, se los citó de cinco en cinco, y se les hizo preguntas como: ¿qué cambiarías de este lugar? ¿Qué te gusta más? ¿Qué te ha parecido esta nueva experiencia sobre tu pueblo?... Además, se le hizo otra entrevista a la maestra del aula para conocer sus impresiones y valoración sobre el 
trabajo desarrollado. Como conclusión, se creó un vídeo de la población y los recorridos a los lugares preferidos, para el que se usó el audio de las voces del alumnado cogidas de las entrevistas grabadas; quedó un resultado bonito y entretenido para los protagonistas de esta experiencia.

En la tabla 2 se hace un resumen del tiempo distribuido para cada actividad, así como de las sesiones:

Tabla 2. Temporización de las actividades.

\begin{tabular}{|l|c|c|}
\hline \multicolumn{2}{|c|}{ Temporización de las actividades } \\
\cline { 1 - 2 } Actividad 1. Dibujar los lugares de la población & $15^{\prime}$ & \multirow{2}{*}{ 1 sesión } \\
\cline { 1 - 2 } Actividad 2. Mapa, fotografías y emociones & $15^{\prime}$ & \\
\cline { 1 - 2 } Actividad 3. Fichas emocionales de la población & $15^{\prime}$ & \\
\hline Entrevistas al alumnado y a la maestra & $40^{\prime}$ & \multirow{2}{*}{1 sesión } \\
\hline Actividad 4. Visualización del vídeo final & $19^{\prime}$ & 1 sesión \\
\hline
\end{tabular}

\section{Resultados y conclusiones}

A partir de los dibujos que hizo el estudiantado sobre los lugares de la población que más gustan, se han obtenido los siguientes resultados:

Tabla 3. Resultados de los lugares que más gustan.

\begin{tabular}{|l|c|c|}
\hline \multicolumn{1}{|c|}{ Lugar } & $\begin{array}{c}\text { Número de niños que lo han } \\
\text { elegido }\end{array}$ & Porcentaje (\%) \\
\hline El castillo & 4 & 22,22 \\
\hline La muralla & 1 & 5,56 \\
\hline El mar & 2 & 11,11 \\
\hline La biblioteca & 1 & 5,56 \\
\hline El estanco & 3 & 16,66 \\
\hline El parque & 2 & 5,56 \\
\hline El molino de arroz & 1 & 5,56 \\
\hline El lavadero & 1 & 11,11 \\
\hline El colegio & 2 & 5,56 \\
\hline El ayuntamiento & 1 & 100 \\
\hline Total & 18 & \\
\hline
\end{tabular}


El lugar favorito del alumnado es el castillo, el segundo es el estanco, en tercer lugar están el mar, el parque y el colegio. Por otra parte, los menos votados son la muralla, la biblioteca, el molino de arroz, el lavadero y el ayuntamiento.

Asimismo, y para completar un poco más los datos registrados, se ha hecho una entrevista a los discentes para saber qué gusta y qué no gusta de cada lugar. Después de una categorización de la información, los resultados más comunes obtenidos son los siguientes:

Lo que más gusta de los siguientes sitios es:

- Del parque: los columpios, los toboganes y jugar con sus amigos.

- Del castillo: las ruinas, las murallas, las vistas al pueblo y escalar la montaña.

- Del estanco: los patos, los peces, el agua, las plantas y el bar.

- Del lavadero: el agua, los peces, el imán para la nevera que hemos hecho en clase y que, antes, las mujeres lavaban la ropa.

- De la biblioteca: los libros para leer.

- Del mar: el agua, la arena, las olas, comer helados, ir con la familia, los peces y los castillos de arena.

- Del colegio: las actividades que hacen en el aula y el patio para jugar.

- Del molino de arroz: el arroz y las paredes.

- Del ayuntamiento: que se ve el cielo reflejado en el edificio y que es muy grande.

- De la muralla: subir arriba de la muralla y que es muy larga.

Lo que menos gusta de los siguientes sitios es:

- Del parque: el bar y la zona de juegos de los más pequeños. Además, harían un parque más grande y para todos.

- Del castillo: es muy pequeño, la subida es muy larga y que no hay dragones.

- Del estanco: no poder bañarse con los patos, el agua sucia y los puentes, que son peligrosos.

- Del lavadero: las vallas y que no se utiliza el lavadero.

- De la biblioteca: que no se puede hablar y que la gente habla.

- Del mar: que se pueden ahogar, las piedras, las algas y el agua cuando está sucia.

- Del colegio: el patio de los mayores porque no tiene columpios ni toboganes, y los árboles que molestan. 
- Del molino de arroz: las cosas viejas y las paredes.

- Del ayuntamiento: las escaleras, las cámaras y no poder jugar.

- De la muralla: las piedras rotas porque pueden hacer mal a la gente al pasar, que no hay ventanas y su forma.

Además, se han obtenido otros resultados centrados en las emociones de los discentes sobre estos diez lugares y sus porqués, donde se puede ver un ejemplo del trabajo en la figura siguiente:

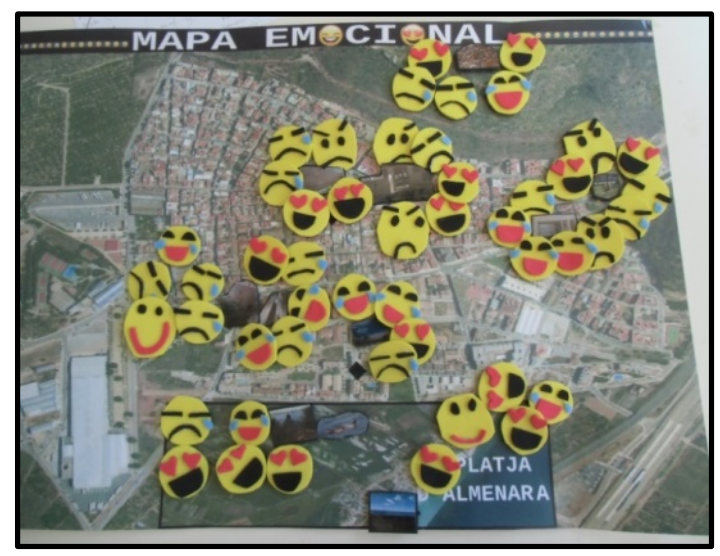

Figura 1. Resultados mapa emocional del equipo 1.

Después de una categorización de la información, los resultados más comunes obtenidos son los siguientes:

Tabla 4. Resultados de las emociones.

\begin{tabular}{|c|c|c|c|c|c|}
\hline Emoción & Lugares & $\begin{array}{c}\text { № } \\
\text { alumnos }\end{array}$ & Emoción & Lugares & $\begin{array}{c}\text { № } \\
\text { alumnos }\end{array}$ \\
\hline \multirow{8}{*}{$\begin{array}{l}\text { 웜 } \\
\text { 음 } \\
\text { 푼 }\end{array}$} & Castillo & 9 & \multirow{8}{*}{ 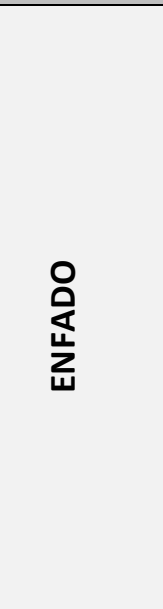 } & Castillo & 1 \\
\hline & Muralla & 4 & & Muralla & 3 \\
\hline & Parque & 8 & & Parque & 1 \\
\hline & Mar & 9 & & Mar & 0 \\
\hline & Biblioteca & 3 & & Biblioteca & 3 \\
\hline & Estanco & 10 & & Estanco & 0 \\
\hline & Lavadero & 6 & & Lavadero & 1 \\
\hline & Ayuntamiento & 5 & & Ayuntamiento & 1 \\
\hline
\end{tabular}




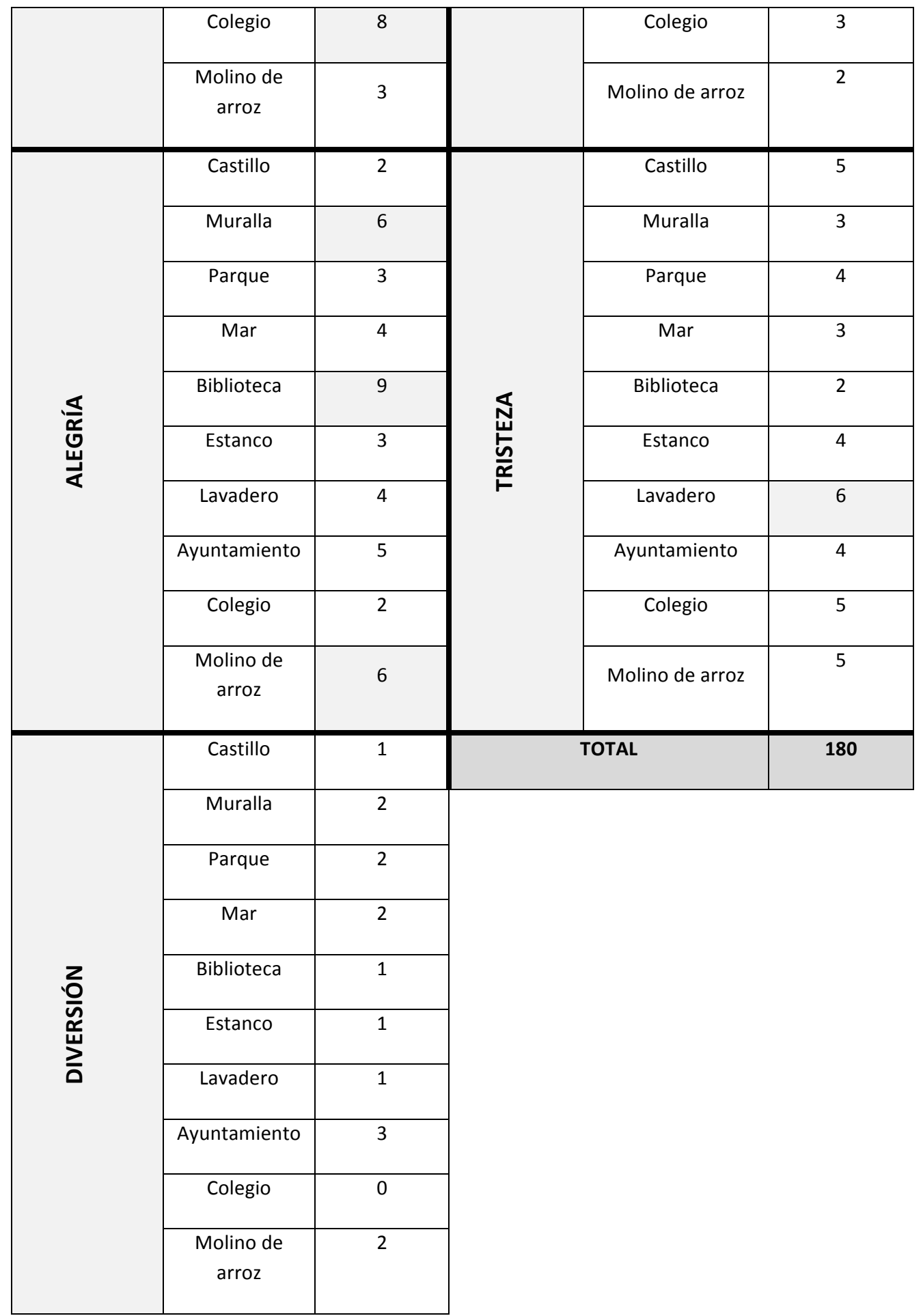

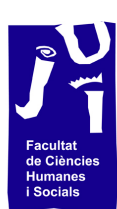

UNIVERSITAT JAUME・I

Cabe destacar que cada niño y niña ha puesto su emoción en cada lugar del mapa de la población y no han repetido. Por tanto, cada uno ha utilizado diez emociones, una por cada lugar de la localidad, y, como son 18 estudiantes, hay un total de 180 emociones diferentes sobre los mismos puntos trabajados. Esto hace que podamos observar los distintos puntos de vista de cada uno y como un mismo lugar puede encantar y desagradar al mismo tiempo. 
Los datos más destacados son que al alumnado les produce felicidad el castillo (porque es bonito), el parque (porque pueden jugar), el mar (porque pueden bañarse, jugar con la arena y estar con la familia), el colegio (porque tienen amigos para jugar) y el lavadero (por los peces); les da alegría la muralla (porque hacen comida muy buena), la biblioteca (porque pueden leer) y el molino de arroz (porque aprenden cosas), y les proporciona tristeza el lavadero (porque tienen malos recuerdos de caídas y aburrimiento), que gusta y entristece al mismo tiempo. Otro aspecto a destacar es la cara enfadada al colegio debido a que no les gusta ir a clase y siempre hacen deberes. Además de estos datos, hay diferentes emociones de otros discentes sobre estos lugares y podemos observar la diversidad de opiniones que tiene el alumnado sobre las partes de su población.

\section{Discusión y conclusiones}

Esta experiencia abre las puertas a nuevas ideas, perspectivas, conocimientos, impresiones e imágenes aportadas por los más pequeños desde los centros escolares, para que las personas adultas no dejen de lado las opiniones relevantes de su entorno, las de los que dicen la verdad, las de los niños. Ellos ofrecen una visión diferente de la población con sus gustos y emociones, además de aportar experiencias junto a sus familiares y amigos. Por tanto, es necesario volver a la autonomía y participación de los más pequeños para mejorar el entorno mediante el juego (Tonucci, 2001).

Un recorrido por la población es lo que se ha hecho. Los niños y las niñas han sido quienes han seleccionado los lugares que han querido trabajar para esta aventura, han sido los protagonistas de su propio aprendizaje. La incorporación de la escuela para mejorar el entorno es necesaria para identificar las carencias, las necesidades y utilizarlas como punto de partida para transformar y crear nuevos espacios comunitarios adaptados al alumnado (Aguirre, Traver y Moliner, 2012).

Para los niños y las niñas, todo esto es nuevo porque se les dejó hablar y expresarse sobre cosas que se pensaban que no iban a importar a nadie, $y$, al darles alas, han reflejado todo lo tenían en la cabeza. Se han sentido importantes, donde todo lo que aportaban era significativo.

No obstante, al realizar las fichas de los tres lugares trabajados, se ha podido profundizar en los porqués de las emociones que sienten por esos puntos de la localidad. Como son resultados genéricos, se han realizado entrevistas grupales de cinco integrantes para conocer lo que más gusta y lo que menos de cada lugar de la población. Con esto, es sorprendente lo que llegan a pensar estos niños de seis y siete años; lo que para un adulto puede no tener nada de importancia, para ellos sí que la tiene. 
Para que el trabajo estuviera completo, se ha querido reflejar en un vídeo todo lo que se ha trabajado dentro del aula. Se ha hecho un recorrido por los diez lugares, desde el que menos gusta hasta el que más. Además, en el vídeo, se han insertado las voces de las entrevistas; así, ellos han podido ver que lo que han trabajado ha tenido una finalidad y pueden verlo en un producto final.

Con todas las entrevistas, se ha podido profundizar sobre qué cambiarían de cada lugar y se han conocido las imperfecciones a través de los ojos de los más pequeños. Durante las actividades, además del trabajo individual, se ha potenciado el aprendizaje y el trabajo cooperativo en el aula. Con esta metodología, se han observado resultados sorprendentes, como la mejora de las relaciones entre el alumnado, la responsabilidad, el clima del aula y la comunicación (Johnson, Johnson y Holubec, 1999; Pujolàs y Lago, 2008; Vera, 2009).

Para concluir, con esta experiencia, se han aprovechado todos los recursos posibles para dar una relación y significado a lo que se ha trabajado. Es un proyecto útil e interesante para poder trabajarlo en todas las localidades, tanto dentro de los centros educativos como en actividades ofrecidas desde las casas de la cultura y los ayuntamientos; gracias a estos proyectos se pueden obtener resultados con propuestas de mejora en diferentes lugares e incluso lo que no modificarían de cada punto. Se trata de ver la población desde los ojos de los niños (Sintes, 2005) para observar la diversidad de opiniones mediante el juego, el diálogo, la comprensión y reflexión (Aguirre, Traver y Moliner, 2012; Sintes, 2005; Tonucci, 2001). Ellos son los que pueden ayudar a mejorar la localidad, ellos son el futuro y, si "hacemos una ciudad a la medida de los niños, haremos una ciudad mejor para todos» (Tonucci, 2001: 34).

\section{Bibliografía}

Aguirre, Arecia, Joan Andrés Traver y Lidón Moliner. 2012. «La escuela incluida. Dinamizando la participación escolar en la comunidad mediante diagnóstico social participativo». Edetania 41: 57-69.

Ayuntamiento de Almenara. Plano turístico de Almenara. Almenara: Patronato de Turismo.

Bisquerra, Rafael (coord.). 2009. Metodología de la investigación educativa. Madrid: La Muralla.

Decreto 108/2014, de 4 de julio, del Consell, por el que establece el currículo y desarrolla la ordenación general de la educación primaria en la Comunitat Valenciana. DOGV núm. 7311: 1632516694. 
Dura López. Francisco. 1972. Almenara. Estudio monográfico. Castellón: Talleres Gráficos Hijos de F. Armengot.

Ferrer Beltran. Pablo. 2002. Memòria gràfica d'Almenara. Un passeig pel segle xx. Almenara: Ajuntament d'Almenara.

Jiménez, Juan Guilló. 2003. «Una ciudad, también, para los más jóvenes». En Una ciudad para los niños: políticas locales de infancia, editado por Carmen Belmonte Useros, 33-42. Madrid: Exlibris.

Johnson, David, Roger Johnson y Edythe Holubec. 1999. El aprendizaje cooperativo en el aula. Buenos Aires: Paidós.

Pujolàs, Pere y José Ramón Lago (coord.). 2008. El programa CA/AC ("Cooperar para aprender/Aprender a cooperar") para enseñar a aprender en equipo. Implementación del aprendizaje cooperativo en el aula. Vic: Universidad de Vic.

Sintes Zamanillo, María. 2005. "Mapa emocional de Segovia». Cuadernos de pedagogía 351: 28-31.

Tonucci, Francesco. 2001. La ciudad de los niños. Madrid: Editorial Graó.

—. 2006. «La ciudad de los niños: ¿Por qué necesitamos de los niños para salvar las ciudades?». Ingeniería y territorio 75: 60-67.

Vera García, María del Mar. 2009. "Aprendizaje cooperativo». Innovación y Experiencias Educativas 14 (enero). https://archivos.csif.es/archivos/andalucia/ensenanza/revistas/c sicsif/revista/pdf/Numero_14/MARIA\%20DEL\%20MAR_VERA_2. pdf. 